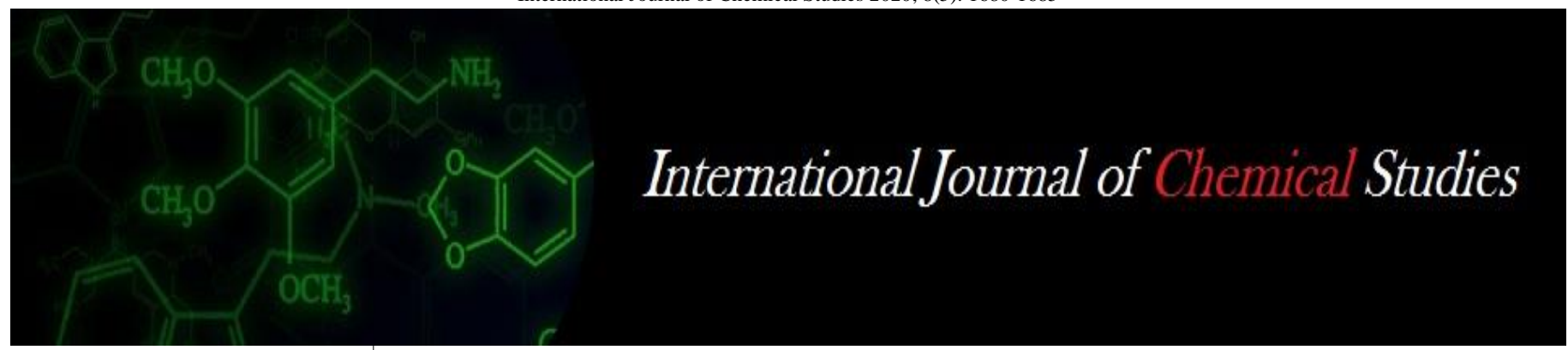

P-ISSN: 2349-8528

E-ISSN: 2321-4902

www.chemijournal.com

IJCS 2020; 8(5): 1680-1685

(C) 2020 IJCS

Received: 10-06-2020

Accepted: 14-07-2020

\section{Deepa J}

Department of Food Process

Engineering, Tamil Nadu

Agricultural University,

Coimbatore, Tamil Nadu, India

\section{Preetha $\mathbf{P}$}

Department of Food Process

Engineering, Tamil Nadu

Agricultural University,

Coimbatore, Tamil Nadu, India

Jeevarathinam G

Department of Food Process

Engineering, Tamil Nadu

Agricultural University,

Coimbatore, Tamil Nadu, India
Corresponding Author:

Deepa J

Department of Food Process

Engineering, Tamil Nadu

Agricultural University,

Coimbatore, Tamil Nadu, India

\section{Evaluating the use of preservatives on the shelf life of tender coconut water}

\author{
Deepa J, Preetha P and Jeevarathinam G
}

DOI: https://doi.org/10.22271/chemi.2020.v8.i5w.10540

\begin{abstract}
Tender coconut water is a sweet, delicious and refreshing natural beverage. The sugar and mineral Constituents attributes to the pleasant taste of tender coconut water. Due to the presence of sugars and a number of plant enzymes, tender coconut water has a strong tendency to undergo biochemical changes and spoilage, once the nut is harvested from the tree. Furthermore, coconut as a whole is bulky and perishable without proper packaging, which challenges the task of transportation of tender coconut water over a long distance. So, an attempt has been made to extend its shelf life in bottles, which will lead to easy transport and easy to serve. Design of the process was developed by considering the dependent variables (microbial population, sensory attributes) and independent variables (time, temperature, preservatives). The preservatives used for this study include potassium sorbate and sodium benzoate. During thermal sterilization process the flavour components were destroyed and palatability was not good and hence in-bottle sterilization was adopted in this study to retain the flavours and preserve tender coconut water. It was found that the tender coconut water preserved by the treatments T11 (Potassium Sorbate (@ $300 \mathrm{ppm}$ ) at $80{ }^{\circ} \mathrm{C}$ for $180 \mathrm{~s}$ ) in the in-bottle sterilization had a shelf life of 3 months and T27 (sodium benzoate (@350 ppm) at $80{ }^{\circ} \mathrm{C}$ for $180 \mathrm{~s}$ ) in the in-bottle sterilization was acceptable with the maximum shelf life of 1 month. By adopting this preservation technique, tender coconut water could be effectively stored and used for 70 days under refrigerated condition $\left(4{ }^{\circ} \mathrm{C}\right)$.
\end{abstract}

Keywords: Tender coconut, preservative, in-bottle sterilization, refrigeration

\section{Introduction}

Coconuts are the fruits of the coconut palm, botanically known as Cocos nucifera L. (nucifera means "nut-bearing") belongs to the family Arecaceae (Palmae), an important member of monocotyledons. Coconut palms are grown in more than 90 countries in the world, with a total production of over 59 million tones in 2016. Most of the world production is in tropical Asia, with Indonesia, Phillippines and India collectively accounting for over $72 \%$ of the world total. The coconut growing area of our country is estimated as 19.33 lakh hectares with an annual production and productivity of about 14.81 million nuts and 6,285 nuts per hectare respectively. According to the statistics of Coconut Development Board (2017) ${ }^{[1]}$, the highest production of coconut in Kerala has been reported as 5968.1 million nuts with an area of 7.97 lakh ha, followed by Tamil Nadu in an area of 6.20 lakh ha (5074.7 million nuts). India exported 15,609 MT of coconuts worth Rs. 90 crores during the year 2016-17 (Ministry of Agriculture, India, 2017) ${ }^{[3]}$. From the total production of coconuts, about $5 \%$ of them is consumed in the form of tender coconut.

Usually coconut water is a mildly acid beverage with a $\mathrm{pH}$ value of approximately 5.5 which can be from slightly cloudy to transparent with a mildly sweet taste. It is constituted mainly of minerals and sugars and, in smaller proportions, nitrogenated substances (amino acids) and fats, as well as vitamins and auxins (growth promoting substances). Due to its salt-rich composition, it is considered to be a natural isotonic fluid. After $2-3$ days of harvest, fermentation takes place and the tender coconut water becomes unfit for consumption and which challenges the task of transportation of tender coconut water over a long distance.

Packaging of sterile tender coconut water as soft drink has a good global market as it ensures availability throughout the year, with consistent quality at reasonable price. A thermal processes such as high temperature and short time pasteurization is used to eliminate the risk of bacteria but also destroy some nutrients and almost the entire delicate flavour present in the coconut water. 
The flavour of tender coconut water is due to the presence of group of delta lactones, which deteriorates at temperatures above $100{ }^{\circ} \mathrm{C}$. An alternative to this, In-bottle sterilization technique inactivates spoilage and pathogenic microorganisms and minimize the quality loss in terms of flavour, colour, nutritional value make it suitable for long term preservation.

The objective of this study was to evaluate the shelf life of coconut water in-bottle sterilization technique with added potassium sorbate and sodium metabisulfite and maintained at refrigerated temperature.

Materials and Methods

Tender coconuts (West Coast Tall variety) of 6-8 months maturity was used immediately after collection and cut open with the help of sterile sharp knife and the water was collected in a clean and sterile container by filtering through a sterile nylon filter under a sterile environment (inside the laminar air flow chamber). For preserving the tender coconut water with in-bottle sterilization along with preservatives were used and independent and dependent variables were fixed. The independent variables include time, temperature and preservatives dosage (potassium sorbate and sodium benzoate). The selected dependant variables were microbial population and sensory attributes (taste, flavour, odour, overall acceptance). The different levels of the independent and dependent variables selected for the study is given below:

Table 1: The Turbidity values of processed TCW at different conditions were presented

\begin{tabular}{|c|c|c|c|c|c|c|c|}
\hline Treatments & $\begin{array}{c}\text { Temperature } \\
(\mathbf{O} \mathbf{C})\end{array}$ & Time $(\mathbf{s})$ & Preservatives $(\mathbf{p p m})$ & Treatments & $\begin{array}{c}\text { Tempe } \\
\text { rapture }\left({ }^{\mathbf{O}} \mathbf{C}\right)\end{array}$ & Time (s) & Preservatives (ppm) \\
\hline $\mathrm{T}_{1}$ & 70 & 240 & Potassium sorbate $(300 \mathrm{ppm})$ & $\mathrm{T}_{17}$ & 70 & 240 & Sodium benzoate $(350 \mathrm{ppm})$ \\
\hline $\mathrm{T}_{2}$ & 70 & 210 & Potassium sorbate $(300 \mathrm{ppm})$ & $\mathrm{T}_{18}$ & 70 & 210 & Sodium benzoate $(350 \mathrm{ppm})$ \\
\hline $\mathrm{T}_{3}$ & 70 & 180 & Potassium sorbate $(300 \mathrm{ppm})$ & $\mathrm{T}_{19}$ & 70 & 180 & Sodium benzoate $(350 \mathrm{ppm})$ \\
\hline $\mathrm{T}_{4}$ & 70 & 150 & Potassium sorbate $(300 \mathrm{ppm})$ & $\mathrm{T}_{20}$ & 70 & 150 & Sodium benzoate $(350 \mathrm{ppm})$ \\
\hline $\mathrm{T}_{5}$ & 75 & 240 & Potassium sorbate $(300 \mathrm{ppm})$ & $\mathrm{T}_{21}$ & 75 & 240 & Sodium benzoate $(350 \mathrm{ppm})$ \\
\hline $\mathrm{T}_{6}$ & 75 & 210 & Potassium sorbate $(300 \mathrm{ppm})$ & $\mathrm{T}_{22}$ & 75 & 210 & Sodium benzoate $(350 \mathrm{ppm})$ \\
\hline $\mathrm{T}_{7}$ & 75 & 180 & Potassium sorbate $(300 \mathrm{ppm})$ & $\mathrm{T}_{23}$ & 75 & 180 & Sodium benzoate $(350 \mathrm{ppm})$ \\
\hline $\mathrm{T}_{8}$ & 75 & 150 & Potassium sorbate $(300 \mathrm{ppm})$ & $\mathrm{T}_{24}$ & 75 & 150 & Sodium benzoate $(350 \mathrm{ppm})$ \\
\hline $\mathrm{T}_{9}$ & 80 & 240 & Potassium sorbate $(300 \mathrm{ppm})$ & $\mathrm{T}_{25}$ & 80 & 240 & Sodium benzoate $(350 \mathrm{ppm})$ \\
\hline $\mathrm{T}_{10}$ & 80 & 210 & Potassium sorbate $(300 \mathrm{ppm})$ & $\mathrm{T}_{26}$ & 80 & 210 & Sodium benzoate $(350 \mathrm{ppm})$ \\
\hline $\mathrm{T}_{11}$ & 80 & 180 & Potassium sorbate $(300 \mathrm{ppm})$ & $\mathrm{T}_{27}$ & 80 & 180 & Sodium benzoate $(350 \mathrm{ppm})$ \\
\hline $\mathrm{T}_{12}$ & 80 & 150 & Potassium sorbate $(300 \mathrm{ppm})$ & $\mathrm{T}_{28}$ & 80 & 150 & Sodium benzoate $(350 \mathrm{ppm})$ \\
\hline $\mathrm{T}_{13}$ & 85 & 240 & Potassium sorbate $(300 \mathrm{ppm})$ & $\mathrm{T}_{29}$ & 85 & 240 & Sodium benzoate $(350 \mathrm{ppm})$ \\
\hline $\mathrm{T}_{14}$ & 85 & 210 & Potassium sorbate $(300 \mathrm{ppm})$ & $\mathrm{T}_{30}$ & 85 & 210 & Sodium benzoate $(350 \mathrm{ppm})$ \\
\hline $\mathrm{T}_{15}$ & 85 & 180 & Potassium sorbate $(300 \mathrm{ppm})$ & $\mathrm{T}_{31}$ & 85 & 180 & Sodium benzoate $(350 \mathrm{ppm})$ \\
\hline $\mathrm{T}_{16}$ & 85 & 150 & Potassium sorbate $(300 \mathrm{ppm})$ & $\mathrm{T}_{32}$ & 85 & 150 & Sodium benzoate $(350 \mathrm{ppm})$ \\
\hline
\end{tabular}

\section{Processing of Tender Coconut Water}

The initial $\mathrm{pH}$ and total sugars of the fresh tender coconut water was determined. The samples were taken and calculated quantity of the preservative was added according to the volume of tender coconut water taken and mixed uniformly. Then the sample was filtered by white muslin cloth. $200 \mathrm{ml}$ of the samples was filled into the sterilized bottles hygienically and sealed manually using a hand operated cap sealing machine. The sealed bottles were placed in the kettle filled with the water and heating was done using a gas stove. A bottle containing tender coconut water was kept open and thermometer was inserted into it to sense the temperature. The tender coconut water was heated to $80^{\circ} \mathrm{C}$ temperature and held for $180 \mathrm{~s}$. After processing the bottles were cooled to room temperature and then stored at $4{ }^{\circ} \mathrm{C}$. The flow chart is given in Fig.1.

\section{Quality Analysis of Tender Coconut Water}

The fresh and processed tender coconut water samples were analyzed for biochemical, microbiological and organoleptic characteristics. The optical properties of the tender coconut water were analyzed as the absorbance, transmittance using spectrophotometer. To evaluate the quality of fresh and processed tender coconut water, Titratable acidity, Total sugars and reducing sugars was determined based on AOAC method 942.15. The $\mathrm{pH}$ was determined using a digital $\mathrm{pH}$ meter (Systronics, Ahmedabad) at $25{ }^{\circ} \mathrm{C}$; the soluble solids using a portable refractometer (ABBE); The color and turbidity parameters were determined in a colorimeter (Hunter Lab Colour flex meter (Hunter Associates Laboratory, Inc.,
Reston, Virgina, USA, digital turbidity meter, Model 331 E, Analytical Lab service, Chennai).

For the microbiological evaluations, the total aerobic plate count was obtained by pour plating $1 \mathrm{~mL}$ of each dilution into Plate Count Agar (PCA). The colonies were counted after 48 hours of incubation at $35{ }^{\circ} \mathrm{C}$ and expressed as Colony Forming Units per $\mathrm{mL}\left(\mathrm{CFU} \cdot \mathrm{mL}^{-1}\right)$. The yeast and mould count was obtained by surface plating $1 \mathrm{~mL}$ of each dilution in Potato Dextrose Agar (PDA) and counting after 5 days at 23 ${ }^{\circ} \mathrm{C}$. The microbiological evaluation was carried out at zero time and at weekly intervals.

\section{Organoleptic Evaluation}

A panel of 5 judges tasted the treated tender coconut water. All judges in the panel were trained with the factors governing the quality of the product. The products were served to each judge who independently examined the characteristics viz., colour, flavour, taste and overall acceptance. The score card was prepared based on 9 point Hedonic scale as shown below:

9 - Like extremely; 8 - Like very much; 7 - Like moderately; 6 - Like slightly; 5 - Neither like nor dislike; 4 - Dislike slightly; 3 - Dislike moderately; 2 - Dislike very much; 1 Dislike extremely. The average score of each character with overall average for the product was then calculated.

\section{Statistical Analysis}

The analyses of the processed coconut water were carried out in triplicate. The analysis of variance (ANOVA) was used to determine significant differences $(P<0.01)$ between different 
coconut water treatments (A, B and C) for every parameter on the same day, and between different storage days for each sample. Following ANOVA, Tukey's means comparisons test was used to assess differences between the means. The software Statistical Analysis System Version 9.2 (SAS) was used in the statistical calculations.

\section{Results and Discussion}

Physico-chemical, Optical and microbiological properties of fresh and processed tender coconut water were recorded and discussed below.

\section{Physico-chemical properties of tender coconut water}

Various physico - chemical properties of fresh and processed tender coconut water were determined and the values are presented in Table 1. From the table, it is seen that the colour of the fresh tender coconut water was recorded in terms of total difference $\Delta \mathrm{E}$ values using Hunter lab colour meter as 0.06 to a maximum of 9.58 which clearly showed that the fresh tender coconut water is colourless. The colour value of distilled water in terms of $\mathrm{L}, \mathrm{a}$ and $\mathrm{b}$ values is 0.04 respectively.

\section{Effect on pH}

Generally, the $\mathrm{pH}$ plays an important role in phenomenon such as enzyme activity, protein denaturation and microbial inactivation kinetics and most microorganisms show increased susceptibility and inability to recover from sublethal injuries at low $\mathrm{pH}$ values. The table also revealed that there were no significant changes in $\mathrm{pH}$ of all the treatments. The fresh tender coconut water was showed a $\mathrm{pH}$ of 4.4 and the processed tender coconut water was slightly acidic in nature with a maximum value of 4.62 due to the addition of preservatives. Similar values of $\mathrm{pH}$ were found to be within the reported range in the literature (Tan et al., 2014) ${ }^{[8]}$.

\section{Effect on TSS}

Total soluble solids (TSS) indicated as the sweetness of TCW and were found in the range of 7.1 to $7.5^{\circ}$ Brix. The obtained values of TSS were found to be within the reported values in the literature (Tan et al., 2014) ${ }^{[8]}$. From ANOVA data it was showing that the inbottle sterilized coconut water had no significant effect $(p<0.05)$ on TSS. However, the maximum deviation obtained in TSS after heat treatment is \pm 0.5 with respect to any replication. The sterilization treatments at different treatment time interval $(150$ - $240 \mathrm{~s})$ showed slight difference in TSS. However, Similar kinds of studies in other commodities such as apple juice, Pineapple juice and lemonmelon juice were reported by Falguera et al., (2011) ${ }^{[2]}$

\section{Effect on titrable acidity}

The Titrable acidity values of in-bottle sterilized TCW at different conditions were presented in Table 1. In this study the Titrable acidity of TCW was expressed as malic acid percentage since malic acid is the dominant organic acid in tender coconut water (Yong et al., 2009) ${ }^{[9]}$. Titrable acidity of coconut water was found to be in the range of 0.062 to 0.079 (\% malic acid). From ANOVA data it was showing that the heat treatment had not significant $(p>0.0001)$ effect on Titrable acidity of TCW. However, the results show that there are slight higher values of Titrable acidity after addition of preservatives to TCW with respect to control (Raw TCW). At different heat treatment conditions there is a negligible change in Titrable acidity value. The reason for such kind of behavior is might be due to the UV light doesn't cause to release the
$\mathrm{H}+$ during the treatment.

\section{Effect on total color difference}

The total color difference values of processed TCW at different conditions with respect to control (unprocessed tender coconut water) were presented in Table 1. The measurement of color is important for the quality assessment of juice. The total color difference was calculated based on $L^{*}, a^{*}, b^{*}$ values. From ANOVA data it was showing that the heat treatment conditions had significant $(p<0.0001)$ effect on total color difference in TCW. The heat treatments at different temperatures such as $70,75,80$ and $85{ }^{\circ} \mathrm{C}$ showed slight changes in total color difference at different time intervals $(150-240 \mathrm{~s})$. The changes in color after heat treatment is due to that the tempertaure impairs some of the pigments present in the juice, either initially present or the ones formed later by the rapid action of polyphenol oxidase (melanins) as well as the Maillard reaction between sugars and amino acids (melanoidins). The maximum changes color difference was observed to be 9.58 after heat treatment. However the total color difference obtained in this study was higher than the study conducted by Falguera et al., (2011) ${ }^{[2]}$ on apple juice. It may due to the variation in properties of sample and treatment conditions.

\section{Effect on Turbidity}

The Turbidity values of processed TCW at different conditions were presented in Table 1 . Generally, turbidity is the cloudiness of a fluid caused by large numbers of individual particles that are generally invisible to the naked eye. It can be defined as a measurement of the degree to which light is scattered by suspended particles and soluble solids in TCW. The turbidity of TCW was found in the range of 4.39 to $8.89 \%$. The obtained values of turbidity are found to be within the reported values in the literature (Tan et al., 2014) ${ }^{[8]}$. From ANOVA data it is showing that the heat treatment conditions (such as temperature, sterilization time and percentage of preservatives) had significant $(p<0.0001)$ effect on turbidity of TCW. However the maximum increase in turbidity after heat treatment is $8.89 \%$ with respect to any replication. So far there is no review available to compare the Turbidity of TCW after heat treatment. However, similar kinds of studies related to pineapple juice was reported by Shamsudin et al., (2014) ${ }^{[7]}$.

\section{Optical properties of tender coconut water \\ Effect on Absorbance and Transmittance of TCW}

Fresh tender coconut water was collected from the selected tender coconuts and used for the preservation studies. From the Table 1, it is observed that the tender coconut water had an absorbance value of $0.154 \mathrm{~cm}^{-1}$. The absorbance of light by the tender coconut water may be due to the suspended particles present in the tender coconut water. Qualls et al., (1983) ${ }^{[5]}$ reported similar results and stated that presence of suspended particles can negatively impact disinfection efficacy due to additional absorbance. Presence of suspended solid particles in the tender coconut water resulted in turbidity value of $4.17 \%$. Transmittance of light through the tender coconut water was $95 \%$. High turbidity value $(8.89 \%)$ of tender coconut water indicated that the tender coconut water contained more suspended solid particles and resulted in lower transmittance value of $91 \%$. Shama et al., (1996) ${ }^{[6]}$ reported similar findings and stated that initial microbial population in liquid foods along with particulates and organic matter were associated with the liquids. 


\section{Organoleptic evaluation}

Mean sensory scores of fresh and processed tender coconut water are presented in Table 1. It is seen from the Table that the fresh tender coconut water recorded a mean score value of 8.4 , which means that it is lying between like extremely and like very much.

Among the different treatment combination in the present study, the treatments with higher shelf life were selected for organoleptic evaluation. From the above said treatments, the treatment namely in-bottle sterilization at $80^{\circ} \mathrm{C}$ for $180 \mathrm{~s}$ using Potassium sorbate (300 ppm) was selected and the mean score was 7.9 which indicates that the sample is comparable with fresh tender coconut water (Table 1).

\section{Microbial load in fresh tender and processed tender coconut water}

The fresh tender coconut water was analyzed for its initial microbial population in order to determine the effect of heat treatment in addition of artificial preservatives and combination of sugar on bacteria, fungi and yeast population using standard procedures and are presented in Table 1 . The preservation technique for the tender coconut water was carried out by the combination of thirty two treatments using in-bottle sterilization technique. In these thirty two treatments, thirty treatments (except treatment $T_{11}$ and $T_{27}$ ) fermented with a foul odour and occurrence of turbidity was noticed in the bottles which were due to the microorganisms. The results obtained for the microbial analysis for the two treatments $T_{11}$ and $\mathrm{T}_{27}$ is presented in Fig 1 .

From the Fig. 1 it is observed that there was a considerable reduction in microbial load during the storage period of 70 days of the samples preserved by Potassium sorbate and an increase in the population of the micro organisms preserved by sodium benzoate under refrigeration. Off flavour not developed in the product preserved by Potassium sorbate after 12 weeks. Off flavour and turbidity was developed in the product preserved by Sodium benzoate after 4 weeks. Thus the treated sample stored at $4^{0} \mathrm{C}$ for Potassium sorbate showed a reduction in microbial population to that of the Sodium benzoate. The results of this study are in line with the results conducted by Pereira et al., (2013) ${ }^{[4]}$ who preserved lime juice with Potassium sorbate preservative.

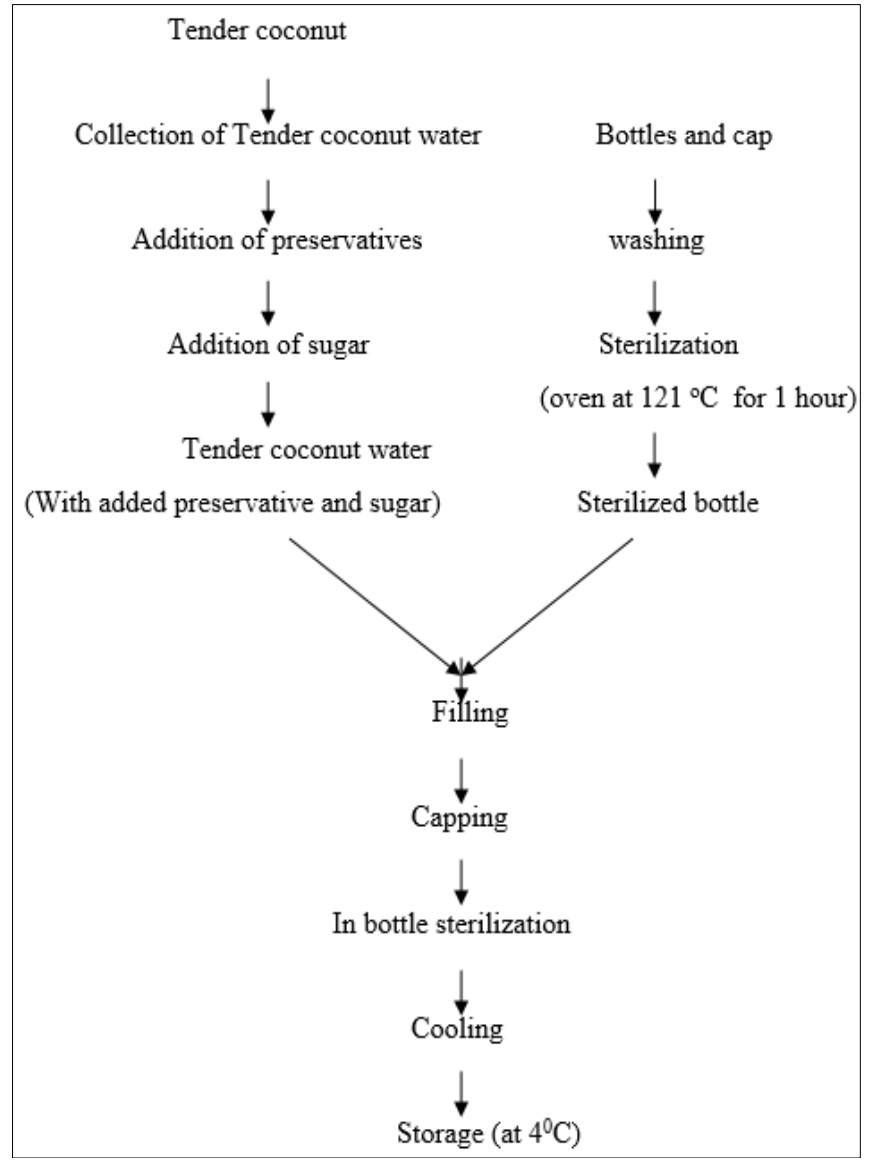

Fig 1: Processing of Tender Coconut Water

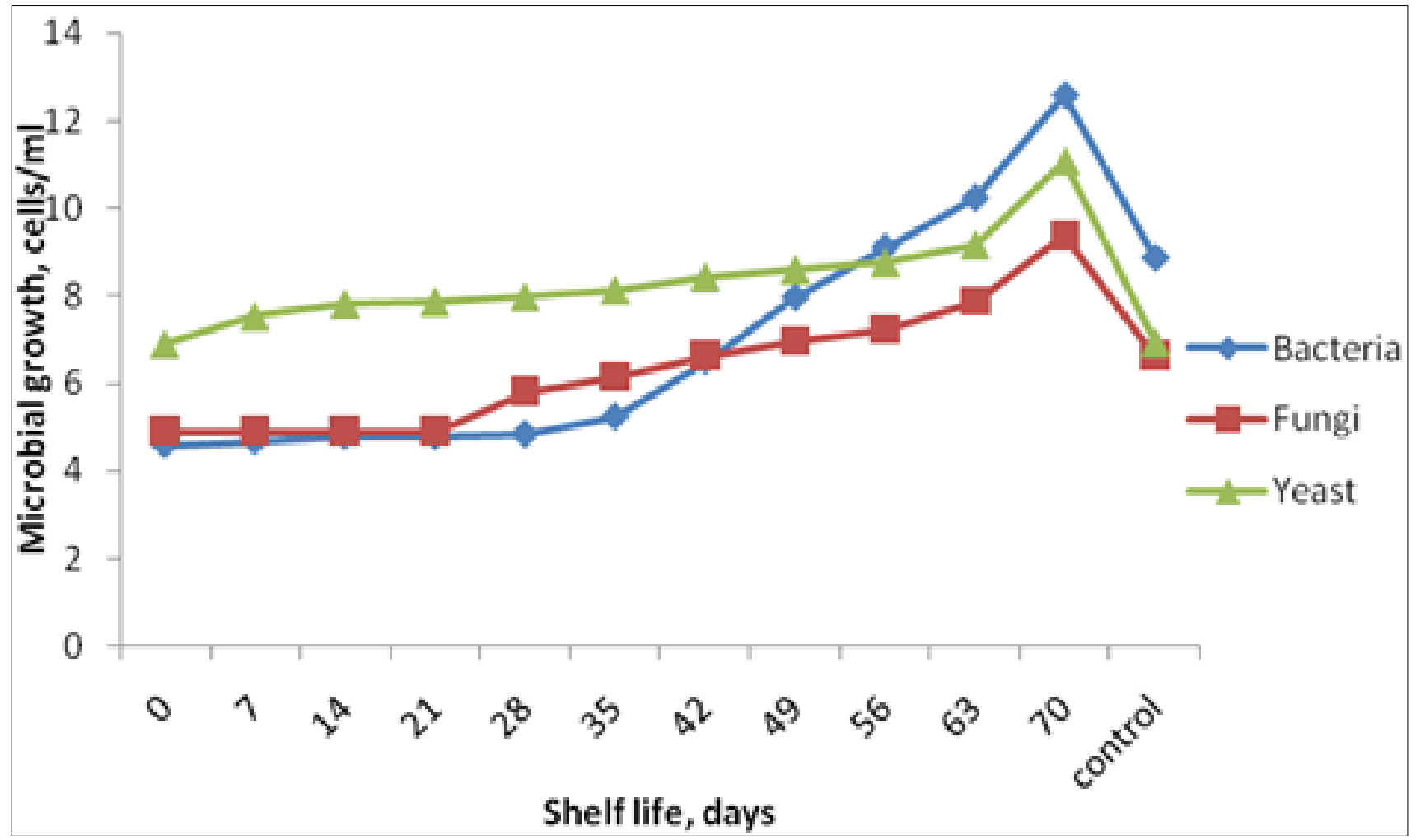

Fig 2: Microbial population of in-bottle sterilized Tender coconut water with potassium sorbate at $80^{\circ} \mathrm{C}$, for 180 s during storage period 


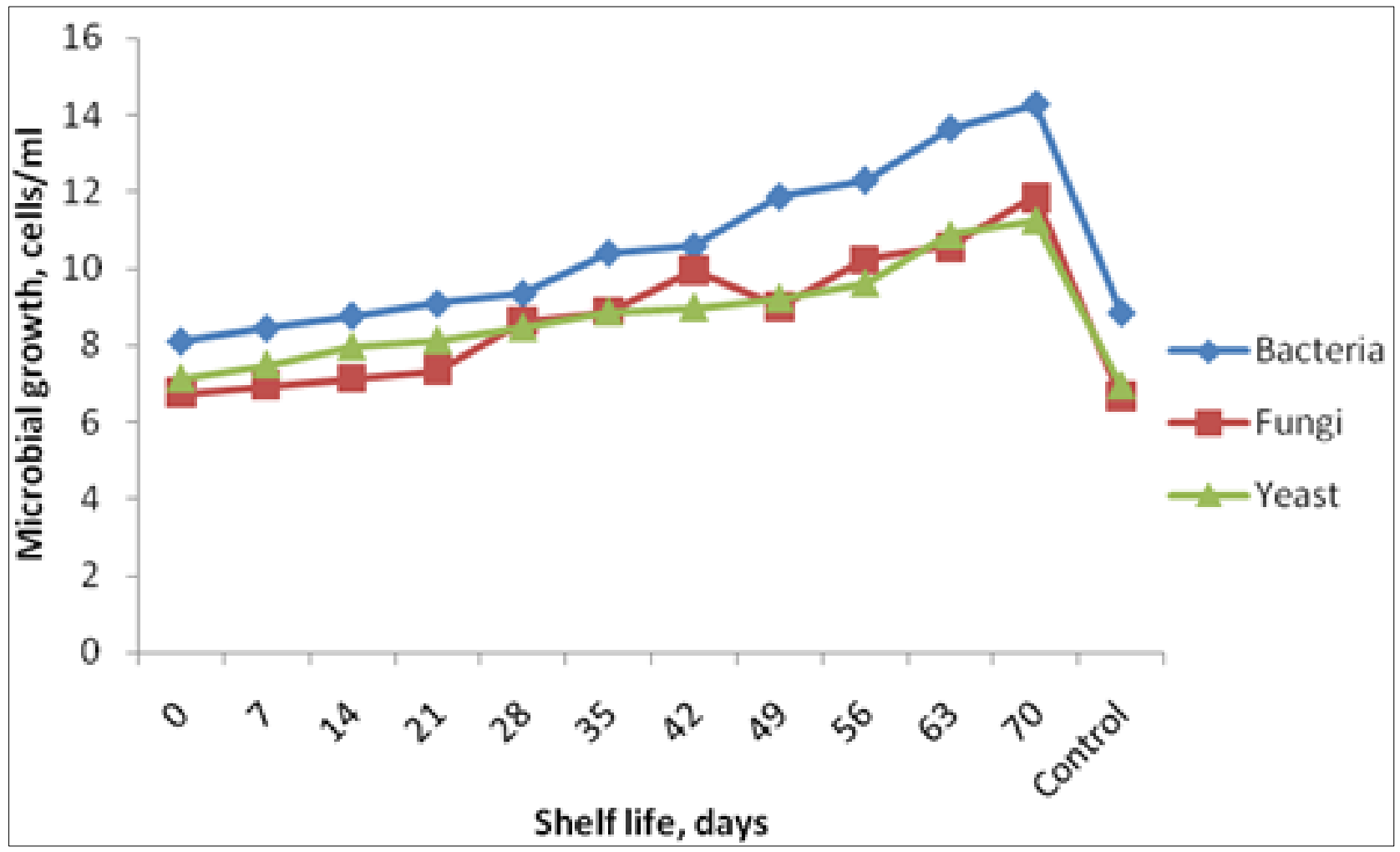

Fig 3: Microbial population of in-bottle sterilized Tender coconut water with sodium benzoate at $80{ }^{\circ} \mathrm{C}$, for 180 s during storage period

Table 1: Physico-chemical and Optical properties of fresh and processed tender coconut water stored under refrigerated condition $\left(4 \pm 2^{\circ} \mathrm{C}\right)$

\begin{tabular}{|c|c|c|c|c|c|c|c|c|c|}
\hline Treatment & Day & $\mathbf{p H}$ & TSS & $\begin{array}{c}\text { Titratable Acidity } \\
\text { (\% malic acid) }\end{array}$ & $\Delta \mathbf{E}$ & $\begin{array}{c}\text { Turbidity } \\
\%\end{array}$ & $\begin{array}{c}\text { Absorbance } \\
\text { per cm }\end{array}$ & Transmittance, $\%$ & $\begin{array}{c}\text { Organoleptic } \\
\text { evaluation }\end{array}$ \\
\hline \multirow{11}{*}{$\begin{array}{c}\mathrm{T}_{11} \\
\text { (Potassium sorbate } \\
@ 300 \mathrm{ppm}-80{ }^{\circ} \mathrm{C} \text { for } \\
180 \mathrm{~s})\end{array}$} & 0 & 4.43 & 7.4 & 0.072 & 0.03 & 5.18 & 0.162 & 96.4 & 8.1 \\
\hline & 7 & 4.41 & 7.4 & 0.072 & 0.10 & 5.06 & 0.396 & 95.1 & 8.1 \\
\hline & 14 & 4.29 & 7.3 & 0.072 & 0.41 & 6.31 & 0.791 & 94.0 & 8.0 \\
\hline & 21 & 4.49 & 7.3 & 0.073 & 0.77 & 7.93 & 0.854 & 93.2 & 8.0 \\
\hline & 28 & 4.42 & 7.3 & 0.073 & 1.72 & 7.97 & 0.945 & 93.1 & 8.0 \\
\hline & 35 & 4.43 & 7.2 & 0.074 & 4.89 & 7.66 & 1.104 & 92.8 & 7.9 \\
\hline & 42 & 4.41 & 7.2 & 0.074 & 6.52 & 7.97 & 1.279 & 92.5 & 7.9 \\
\hline & 49 & 4.44 & 7.2 & 0.075 & 7.29 & 8.27 & 1.362 & 92.0 & 7.8 \\
\hline & 56 & 4.45 & 7.2 & 0.076 & 8.68 & 8.47 & 1.431 & 91.7 & 7.8 \\
\hline & 63 & 4.48 & 7.2 & 0.077 & 8.99 & 8.52 & 1.578 & 91.3 & 7.8 \\
\hline & 70 & 4.51 & 7.1 & 0.079 & 9.12 & 8.89 & 1.662 & 91.0 & 7.6 \\
\hline \multirow{11}{*}{$\begin{array}{c}\mathrm{T}_{27} \\
\text { (Sodium benzoate } \\
@ 350 \mathrm{ppm}-80^{\circ} \mathrm{C} \text { for } \\
180 \mathrm{~s})\end{array}$} & 0 & 4.43 & 7.5 & 0.072 & 0.04 & 4.39 & 0.156 & 97.0 & 8.2 \\
\hline & 7 & 4.43 & 7.5 & 0.072 & 0.12 & 4.71 & 0.298 & 96.2 & 8.2 \\
\hline & 14 & 4.40 & 7.4 & 0.073 & 0.30 & 5.13 & 0.856 & 95.4 & 8.2 \\
\hline & 21 & 4.49 & 7.4 & 0.073 & 0.51 & 5.66 & 1.221 & 94.3 & 8.0 \\
\hline & 28 & 4.43 & 7.4 & 0.074 & 1.85 & 6.04 & 1.368 & 93.9 & 8.0 \\
\hline & 35 & 4.45 & 7.4 & 0.075 & 3.50 & 6.53 & 1.489 & 93.1 & 7.9 \\
\hline & 42 & 4.42 & 7.3 & 0.076 & 5.98 & 6.82 & 0.832 & 92.8 & 7.9 \\
\hline & 49 & 4.45 & 7.3 & 0.077 & 6.63 & 7.12 & 0.916 & 92.2 & 7.9 \\
\hline & 56 & 4.48 & 7.2 & 0.077 & 7.36 & 7.35 & 1.312 & 91.9 & 7.8 \\
\hline & 63 & 4.51 & 7.2 & 0.078 & 8.12 & 8.03 & 1.459 & 91.5 & 7.8 \\
\hline & 70 & 4.62 & 7.1 & 0.079 & 9.58 & 8.57 & 1.564 & 91.2 & 7.7 \\
\hline Fresh coconut water & 0 & 4.40 & 7.4 & 0.062 & 0.06 & 4.17 & 0.154 & 95.0 & 8.4 \\
\hline
\end{tabular}

\section{Conclusion}

Shelf life of a product is defined as the length of time they remain not only marketable but also consumer acceptable with safe quality. Processed tender coconut water was stored at low temperatures $4^{0} \mathrm{C}$ in order to extend the shelf life.

The tender coconut water treated by in-bottle sterilization using potassium sorbate $\left(300 \mathrm{ppm}\right.$ at $80^{\circ} \mathrm{C}$ for $3 \mathrm{~min}$ ) as a preservative has recorded the highest sensory score value of 7.9 with a shelf life of 70 days at refrigerated condition $4^{0} \mathrm{C}$ in glass bottle. This treatment combination contains microbial population less than the fresh tender coconut water.
References

1. CDB. Coconut Database. Coconut Development Board, Government of India, 2017.

2. Falguera V, Pagán J, Ibarz A. Effect of UV irradiation on enzymatic activities and physicochemical properties of apple juices from different varieties. LWT-Food Science and Technology. 2011; 44(1):115-119.

3. Ministry of Agriculture. Horticulture Division. Govt. of India, 2017.

4. Pereira EPR, Faria JAF, Pinto UM. Optimizing the Use of Potassium Sorbate and Sodium Metabisulphite for the 
Chemical and Microbial Stability of Carbonated Coconut Water. Braz J Food Technol. 2013; 16:125-132.

5. Qualls RG, Johnson JD. Bioassay and dose measurement in UV disinfection. Applied and Environmental Microbiology. 1983; 45(3):872-877.

6. Shama G, Peppiatt C, Biguzzi M. A novel thin film photoreactor. Journal of Chemical Technology and Biotechnology. 1996; 65:56-64.

7. Shamsudin R, Adzahan NM, Yee YP, Mansor A. Effect of repetitive ultraviolet irradiation on the physicochemical properties and microbial stability of pineapple juice. Innovative Food Science \& Emerging Technologies. 2014; 23:114-120.

8. Tan TC, Cheng LH, Bhat R, Rusul G, Easa AM. Composition, physicochemical properties and thermal inactivation kinetics of polyphenol oxidase and peroxidase from coconut (Cocos nucifera L) water obtained from immature, mature and overly-mature coconut. Food Chemistry. 2014; 142:121-128.

9. Yong JW, Ge L, Ng YF, Tan SN. The chemical composition and biological properties of coconut (Cocos nucifera L.) Water Molecules. 2009; 14(12):5144-5164. 